\title{
La grippe aviaire : Sommes-nous prêts?
}

$\mathrm{J}$ usqu'à maintenant, presque tous les 69 cas d'infection humaine par le virus de la grippe aviaire signalés depuis janvier 2004 mettaient en cause des personnes qui vivaient avec de la volaille ou travaillaient avec de la volaille, de la viande de volaille ou des œufs en Asie du Sud-Est. Pourquoi ces cas relativement peu nombreux suscitent-ils autant de commentaires à l'échelle du globe et font-ils craindre une épidémie mondiale semblable aux pandémies de 1957, de 1968 et, bien entendu, de 1918? (Voir les articles du FAMC en ligne sur l'épidémie de 1918 à www.cmaj.ca/cgi/content /full/172/8/965/DC1.) L'infection par le virus de la grippe aviaire - qui a fait l'objet récemment d'une analyse dans le $7 A M C^{1}$ - est très répandue chez les oiseaux. Comme les oiseaux et les êtres humains ont des récepteurs viraux spécifiques à leur espèce, l'infection par le virus de la grippe aviaire est rare chez les êtres humains, mais lorsqu'elle se produit, elle découle probablement de mutations virales spontanées.

On craint une pandémie parce que le virus est très pathogène chez les êtres humains - il a causé la mort dans 46 des 69 cas signalés - et parce que l'incidence est à la hausse chez les êtres humains. Jusqu'à maintenant, on a démontré qu'un seul des 69 cas humains résultait d'une transmission entre êtres humains, mais une autre mutation pourrait permettre au virus de franchir cette barrière.

Les trois facteurs qui doivent converger pour qu'il y ait éclosion d'une épidémie mondiale d'infection par le virus de la grippe A humaine $(\mathrm{H} 5 \mathrm{~N} 1)$ sont le contact fréquent entre des êtres humains et des oiseaux infectés (qui augmente les risques qu'un virus muté récemment infecte un être humain), une maladie humaine qui a une longue phase prodromique (qui rend difficile la détection précoce) et une surveillance médiocre (qui réduit les chances de confinement précoce). Ces trois conditions existent en Asie du Sud-Est.

Les caractéristiques de l'élevage familial type de volailles en Asie du Sud-Est - oiseaux vivant tout près des êtres humains (partagent souvent le même toit) et des habitudes commerciales comportant la vente de poulets vivants sur les marchés locaux et qui font que les animaux sont abattus au point de vente ou dans la cuisine familiale - se conjuguent toutes pour placer les êtres humains en contact étroit avec des oiseaux infectés, leur viande ou leurs œufs. Ces conditions sont idéales pour permettre à un virus de muter et d'infecter des hôtes humains.

La détection rapide des cas humains et leur mise en quarantaine rapide pourraient interrompre la transmission entre êtres humains. Contrairement au SRAS, toutefois, la grippe aviaire semble avoir une phase sous-clinique importante. Par exemple, deux enfants apparentés de la province de Dong Thap, dans le sud du Vietnam, avaient une diarrhée non spécifique depuis des jours avant l'apparition des symptômes respiratoires et neurologiques (coma) caractéristiques causés par le virus $\mathrm{H} 5 \mathrm{~N} 1 .^{2}$ On a récupéré le virus vivant dans les selles des enfants. Actuellement, la surveillance de la maladie (encore insuffisante dans les pays industrialisés et sporadique dans le monde en développement) ne fera pas grand chose pour aider à identifier rapidement les êtres humains qui ont la grippe aviaire et il n'y a pas de test de laboratoire qui permet d'identifier rapidement le virus vivant.

Sommes-nous prêts? La démarche du Canada est typique de la plupart des pays occidentaux : on a mis l'accent sur le développement rapide d'un vaccin, en supposant, ce qui est raisonnable, que la pandémie commencera en Asie et, ce qui ne l'est pas, qu'on aura le temps d'identifier le virus et de produire les quantités massives de vaccin nécessaires. Les plans du monde occidental qui prévoient interrompre les voyages en avion en provenance des pays infectés ont très peu de chance d'être efficaces ou appliqués à temps. Il peut être utile de stocker des doses du seul agent antiviral efficace (oseltamivir), mais la phase prodromique non spécifique de la maladie et le fait que l'oseltamivir est efficace seulement s'il est pris au cours des premiers jours de l'infection entravent considérablement cette stratégie (même si le médicament peut être utile si les personnes qui ont eu des contacts avec le patient le prennent comme prophylaxie ${ }^{3}$ ). Il importe de signaler qu'une telle planification narcissique ne fait rien pour les populations de l'Asie du Sud-Est et des autres régions du monde en développement.

La seule façon efficace d'enrayer une pandémie globale, c'est de la stopper en Asie du Sud-Est. Même si leur effet sera probablement limité, il faut stocker des réserves d'oseltamivir partout en Asie du Sud-Est.

À long terme, nous devons modifier les méthodes d'élevage dans la majeure partie du monde, non seulement comme mesure économique, mais aussi comme initiative de santé publique. On pourrait réduire considérablement les risques en limitant l'élevage de la volaille aux grandes entreprises commerciales semblables à celles de l'Occident, où le contact entre les êtres humains et les oiseaux est limité et contrôlé et où il est possible de repérer et d'éliminer rapidement les oiseaux infectés. Une telle pratique réduirait les risques de voir des virus mutants qui existent chez des oiseaux et d'autres animaux trouver des hôtes humains. Nous aurions dû tirer des leçons des expériences que nous avons vécues avec le SRAS. De toute évidence, nous ne l'avons pas fait. - $7 A M C$

\section{Références}

1. Weir E, Wong T, Gemmill I. Avian influenza outbreak: update. $7 A M C$ 2004;170(5):785-6.

2. de Jong MD, Cam BV, Qui PT, Hien VM, Thanh TT, Hue NV, et al. Fatal avian influenza $\mathrm{A}(\mathrm{H} 5 \mathrm{~N} 1)$ in a child presenting with diarrhea followed by coma. NEngl 7 Med 2005;352:686-91.

3. Monto AS. The role of antivirals in the control of influenza. Vaccine 2003; 21:1796-800. 